\title{
DIVERSIDADE CULTURAL VERSUS HOMOGENEIZAÇÃO: UM OLHAR SOBRE A BASE NACIONAL COMUM CURRICULAR E SUAS IMPLICAÇÕES NA EDUCAÇÃO BÁSICA
}

\section{ARTIGO ORIGINAL}

ALVES, Manoel Messias Santos ${ }^{1}$

SANTOS, Willian Lima ${ }^{2}$

OLIVEIRA, Eliel Souza de ${ }^{3}$

ALVES, Manoel Messias Santos. SANTOS, Willian Lima. OLIVEIRA, Eliel Souza de. Diversidade cultural versus homogeneização: um olhar sobre a Base Nacional Comum Curricular e suas implicações na Educação Básica. Revista Científica Multidisciplinar Núcleo do Conhecimento. Ano 05, Ed. 08, Vol. 03, pp. 181-191. Agosto de 2020. ISSN: 2448-0959, Link de acesso: https://www.nucleodoconhecimento.com.br/educacao/implicacoes-naeducacao

\section{RESUMO}

Entre os principais assuntos mais discutidos no cenário sociopolítico da educação nacional, a implementação da Base Nacional Comum Curricular (BNCC) tem ganhado destaque. Através de uma análise documental e bibliográfica, o presente artigo objetiva promover uma reflexão das propostas curriculares elencadas na BNCC e

1 Doutorando em Educação (PPGED/UFS). Mestre em Ensino de Ciências e Matemática (PPGECIMA/UFS). Bacharel em Enfermagem (UNIAGES).

${ }^{2}$ Mestrando em Educação (PPGED/UFS). Especialista em Tecnologias e Educação Aberta e Digital (UFRB). Licenciado em Pedagogia (FANEB).

${ }^{3}$ Especialista em Docência no Ensino Superior (UCAM). Licenciado em Biologia (UNIAGES). 
suas implicações na diversidade cultural. Apontamos no decorrer do texto a necessidade de se analisar criticamente os pressupostos curriculares da Base Nacional, juntamente com as dimensões didáticas, políticas e administrativas com o intuito de promover a socialização e a concretização dos fins sociais e culturais, pois a ausência dessa reflexão desencadeia um discurso universalista capaz de provocar uma imagem negativa e homogeneizante do currículo escolar. Os debates provocados nesse trabalho apontam que não é possível e nem necessário à existência de um mesmo currículo para todas as escolas, pois o currículo precisa ser construído contextualmente para fazer sentido e acolher as demandas e necessidades locais. No entanto, essa abordagem constitui um desafio predominante na atualidade devido à manutenção de uma ideologia pedagógica ultrapassada e alienada às questões de controle e dominação.

Palavras-chave: BNCC, currículo escolar, diversidade cultural.

\section{INTRODUÇÃO}

A implementação da Base Nacional Comum Curricular (BNCC) tem sido um dos assuntos mais discutidos no atual cenário sociopolítico da educação brasileira. Tratase de um documento de caráter normativo, criado para conduzir o que deve ser ensinado nas escolas de Educação Básica em todo o país, desde a modalidade da Educação Infantil até o Ensino Médio (BRASIL, 2018).

A construção de um documento oficial curricular comum já estava prevista na Constituição Federal de 1988 (BRASIL, 1988), assim como também na Lei de Diretrizes e Bases da Educação Nacional (LDBEN) - Lei no 9.394, de 20 de dezembro de 1996 - (BRASIL, 1996), e se consolidou recentemente como meta do Plano Nacional de Educação (PNE) no período de vigência de 2014-2024. Dessa forma, foi por meio da formulação da LDBEN de 1996, que as disciplinas obrigatórias de cada núcleo comum foram determinadas e se mantiveram presentes em todos os currículos do Ensino Fundamental e Médio das entidades de ensino públicas ou privadas no país. 
A primeira versão da BNCC foi redigida em 2014, contemplando somente os Ensinos Infantil e Fundamental, e no ano seguinte foi aberto para consulta pública, permitindo que a sociedade de maneira geral, sobretudo representantes da educação e o setor empresarial, pudessem contribuir para sua segunda reformulação que ocorreu no ano de 2016, sendo debatida na forma de seminários com a participação de todos os estados brasileiros, e por sua vez, resultou em sua terceira versão mediante um novo ciclo de debates no ano posterior.

Dessa forma, a BNCC para a Educação Infantil e o Ensino Fundamental foi aprovada e homologada no final de 2017 por meio de audiências e consultorias públicas, enquanto o texto referente ao Ensino Médio teve sua aprovação e homologação pelo Conselho Nacional de Educação (CNE) e pelo Ministério da Educação em 2018. Apesar dessa discussão acerca da necessidade de se criar um currículo comum que atenda as demandas de todas as escolas do território nacional, considerando suas particularidades regionais, sociais e metodológicas de cada instituição, convém repensar se de fato os pressupostos da BNCC atendem a vasta diversidade cultural existente no país, ou ao contrário do foi divulgado, suas definições de competências e habilidades, tidas como essenciais, não são mais uma forma de hegemonizar os interesses dos agentes políticos públicos e privados? (BRASIL, 2018).

Nesse contexto, o presente artigo tem como objetivo principal promover uma reflexão das propostas curriculares elencadas na BNCC e suas implicações na diversidade cultural. Em face dessa discussão, será que é possível uma Base Nacional ${ }^{[4]}$, unificadora e homogeneizadora da educação num país tão desigual, diversificado e multicultural como o Brasil? Para fundamentar essa discussão recorremos a uma análise documental e bibliográfica.

\section{O CURRÍCULO E SUA PRODUÇÃO HISTÓRICA E CONTEXTUAL}

As discussões referentes ao currículo correspondem a uma das problemáticas mais antigas e complexas na área da educação, sua terminologia é originada da palavra latina curriculum (cuja raiz etimológica advém de cursus e currere), e de acordo com Sacristán (2013), esses termos eram utilizados na Roma Antiga para representar a 
soma das "honras" que os cidadãos acumulavam ao longo de sua trajetória política e profissional. Dessa forma, o termo currículo teve suas primeiras utilizações na Idade Média, cujo conceito correspondia a organização dos segmentos e fragmentos dos conteúdos, de forma ordenada com a função organizadora e unificadora das estratégias de ensino e aprendizagem (ALVES; SANTOS, 2017).

Em sua origem, o currículo significava o território demarcado e regrado do conhecimento correspondente aos conteúdos que professores e centros de educação deveriam cobrir; ou seja, o plano de estudos proposto de imposto pela escola aos professores (para que 0 ensinassem) e aos estudantes (para que o aprendessem) (SACRISTÁN, 2013, p. 17, grifo do autor).

Percebe-se que desde os primórdios o significado de currículo está relacionado à ideia de seleção de conteúdos e de ordem na classificação dos conhecimentos que serão ensinados, limitando assim, a autonomia dos professores no processo de ensino e aprendizagem, pois determina quais são os elementos essenciais para 0 desenvolvimento escolar dos estudantes. Para Sacristán (2013), devido às mudanças econômicas, políticas e culturais ocorridas nos séculos XVI e XVII, o currículo assumiu o papel de uma invenção decisiva para a estruturação do atual entendimento de escolaridade e em conformidade com o conjunto de experiências a serem vividas pelo aluno.

No entanto, essa concepção ultrapassada de delimitar o currículo e seus componentes pela separação entre as matérias ou disciplinas que o compõem, perdeu fôlego no decorrer dos anos, pois de modo geral, sabemos que o currículo escolar abrange toda a prática educativa e suas funções socioculturais, influenciando os subsistemas relacionados com o significado pedagógico nas esferas políticoadministrativo; participação social e controle; ordenação do sistema educativo; produção de meios; criações culturais e científicas; técnico-pedagógico; inovação; e prático pedagógico (SACRISTÁN, 2000). Com outras palavras, o currículo corresponde a um instrumento político que se vincula à ideologia, à estrutura social, à cultura e ao poder (OLIVEIRA; ARAÚJO; CAETANO, 2012), e por esse motivo, consideramos relevante analisar qual currículo vem sendo preconizado na BNCC e 
nos demais documentos que determinam o que deve ser ensinado e obedecido nas escolas.

Numa abordagem mais contemporânea, Silva (1999), considera que o currículo representa formas de seleção da cultura mediante práticas de significação em meio de conflitos e de relações de poder, que resultam nas identidades sociais. Assim, ao refletir sobre a concepção de currículo e sua contribuição social e cultural nas instituições de ensino, sobretudo no que se refere a prática pedagógica, defendemos a magnitude de se promover um currículo que contemple a diversidade cultural na Educação Básica, algo que parece estar cada vez mais esquecido nas atuais propostas do governo.

Embora esses diferentes conceitos e significados de currículo apontem um direcionamento de uma ordem por meio da regulação do conteúdo da aprendizagem e ensino na escolarização moderna, convém ressaltar que no contexto brasileiro essas discussões curriculares apareceram com maior destaque tardiamente na produção e contextualização do pensamento educacional, tanto na literatura científica, quanto nos debates entre os educadores devido a expansão das obras e documentos oficiais publicados a partir da década 1990, como por exemplo, a LDBEN e os Parâmetros Curriculares Nacionais (PCN), juntamente com a influência de modelos internacionais que perduram até a atualidade e que culminaram na produção da BNCC.

Nessa perspectiva, defendemos que ao invés de exaltar ou considerar a BNCC como um documento milagroso capaz de resolver todos os problemas que circundam o atual cenário da educação, se faça uma análise crítica de seus pressupostos curriculares, didáticos, políticos, administrativos e seus valores com o intuito de promover a socialização e a concretização dos fins sociais e culturais.

Assim, esperamos que essa discussão contribua para conscientização de que o currículo corresponde a um instrumento político que se vincula à ideologia, à estrutura social, à cultura e ao poder, e por isso, ao invés de ficar inerte ao conformismo imposto pela Base Nacional, que a comunidade escolar e acadêmica busque analisar qual 
currículo deve ser ensinado e seguido nas escolas, para conhecer seu verdadeiro significado e finalmente conscientizar-se da existência de um currículo oculto e sua relevância na construção de identidades e subjetividades (OLIVEIRA; ARAÚJO; CAETANO, 2012).

\section{REFLEXÕES SOBRE A VISÃO MULTICULTURAL (OU HOMOGENEIZADORA) DO CURRÍCULO ESTABELECIDA NA BASE}

A diversidade cultural, ou multiculturalismo, representa um campo teórico e político voltado para a valorização da pluralidade cultural e formação da cidadania, motivo pelo qual sua valorização não deve ficar de fora do currículo escolar, pois seus pressupostos favorecem a formação de indivíduos críticos, comprometidos com o respeito à multiculturalidade e aptos a se inserirem num mundo global. Nesse sentido "a educação tem uma dimensão muito maior do que meramente ensinar e instruir" (OLIVEIRA et.al 2019, p. 110).

Apesar da BNCC não consistir exclusivamente em uma dimensão curricular, e sim como uma referência norteadora para que os currículos de cada escola do país estejam sincronizados a ela, ressaltamos que essa articulação tida como certa e estabelecida, corresponde a um discurso universalista capaz de provocar uma imagem negativa e homogeneizante do currículo escolar (LOPES, 2018). Por outro lado, na medida em que o currículo passa a ser visto como uma construção social, este assume uma visão multicultural para se defrontar com as desigualdades sociais e culturais, trabalhando em prol da formação das identidades abertas à pluralidade, em uma perspectiva de educação para a cidadania ética, que respeita e valoriza as relações interpessoais (SILVA, 1999).

$\mathrm{Na}$ concepção de Lopes (2018), não é sensato pensar numa homogeneização da educação num país tão diversificado e desigual quanto ao nosso, tampouco adotar a ideia reducionista da educação à níveis de aprendizagem mensurados por testes padronizados e de que todos os alunos terão um aprendizado uniforme. Silva (1999) reforça essa discussão ao defender que o multiculturalismo é um importante 
instrumento de luta política que não pode ser separado das relações de poder inerentes do currículo, tendo em vista que:

[...] transfere para o terreno político uma compreensão da diversidade cultural que esteve restrita, durante muito tempo, a campos especializados como o da Antropologia [...] para tornar aceitável a ideia de que não se pode estabelecer uma hierarquia entre culturas humanas, de que todas as culturas são epistemológica e antropologicamente equivalentes (SILVA, 1999, p. 86).

Nessa conjuntura, a centralidade curricular imposta pela Base Nacional é reflexo dos cenários internacionais e documentos curriculares anteriores a sua aprovação. Para Lopes (2018), as orientações para o currículo não devem se limitar a esses documentos, e sim buscar respaldo na literatura educacional, na formação inicial e continuada docente, nos projetos em parcerias com Universidades e escolas e em demais ações que constituem o que seria na visão de Silva (1999), o currículo oculto.

Acompanhando esse raciocínio, não é difícil perceber que a BNCC carece de uma maior contextualização acerca do currículo, tendo em vista que não foi problematizado o entendimento do que seria um currículo comum, ou um conhecimento comum propagado em suas práticas pedagógicas, consideradas essenciais. Lopes (2018, p. 25), faz um alerta contra a pretensão da Base Nacional "de que todas escolas sigam a mesma proposta curricular e a mesma orientação pedagógica", em que na visão da autora, as propostas atuais, tanto do jeito que estão redigidas, quanto da forma que é praticada, tendem a ocultar a problemática de que a desigualdade social associada à educação não é decorrente de um registro intrinsecamente pedagógico.

Essa autora corrobora ainda ao apontar que além de não existir necessidade de que todas escolas tenham o mesmo currículo, também não é possível que esse currículo seja igual em todo o território nacional, pois o currículo precisa ser construído contextualmente para fazer sentido e acolher a infinidade de demandas e necessidades, que estão longe de serem homogêneas, já que estudantes diferentes não produzem e nem compartilham os mesmos saberes e experiências de vida. Entretanto, Lopes (2018, p. 26) enfatiza que: 
Mesmo não sendo possível a constituição dessa homogeneidade curricular, via BNCC ou qualquer outra organização centralizada do currículo, insiste-se no projeto de uma base unificadora $e$ homogeneizadora, sob o argumento de que a qualidade da educação depende desse projeto.

Muito se fala em qualidade da educação na Base, mas assim como aponta o autor mencionado, essa noção de qualidade não está problematizada de maneira satisfatória, muitas vezes ficando reduzida a um superficial entendimento de qualidade de ensino mensurado pela assimilação de conteúdos demonstrada por meio de avaliações da aprendizagem em larga escala, como as avaliações do Sistema de Avaliação do Ensino Básico (SAEB), instituído em 1990 pelo Instituto Nacional de Estudos e Pesquisas Educacionais Anísio Teixeira (INEP), e que atualmente é composto por um conjunto de avaliações com finalidade diagnóstica de auferir os indicativos da qualidade de ensino, e consequentemente da Educação Básica do país (INEP, 2017; ALVES, 2018).

É notório que as avaliações do SAEB, assim como em outros sistemas de avaliação estaduais e municipais, a ideia de qualidade da educação permanece limitada aos resultados das proficiências dos estudantes nesses exames, sem ao menos considerar os demais elementos existentes no processo pedagógico das escolas (ALVES, 2018). Essa centralidade do currículo à avaliação é apontada por Lopes (2018), como uma tentativa de homogeneização e comparação de saberes, na qual o conhecimento é tratado como um dado, ou seja, algo capaz de ser distribuído e avaliado uniformemente para todos os estudantes. A autora defende que a essência da educação transcende as estratégias de transmitir conteúdos e de mensurar resultados em testes de desempenho, motivo pelo qual o currículo precisa atender a constante dinâmica da diversidade cultural.

Nessa perspectiva, um dos maiores desafios da educação atual é combater esse caráter excludente dos currículos, precursor de desigualdades sociais e que muitas vezes preza por padrões culturais distintos da realidade dos alunos (SILVA, 1999). Por isso, para se pensar num aspecto multicultural do currículo é necessário a inclusão dos grupos minoritários nos diferentes debates e contextos sociais, ampliando essa 
discussão nas práticas educativas voltadas ao planejamento curricular e prevenindo assim, à desvalorização e/ou discriminação das experiências dos estudantes, bem como a criação de rótulos e a valorização de determinadas culturas, consideradas elitizadas e hegemônicas.

Com efeito, ao invés de estabelecer um currículo padronizado e global, a BNCC precisa levar em consideração que os conhecimentos exigidos nos atuais testes de desempenho escolar podem confrontar com outros conhecimentos prévios e alternativos dos alunos, dessa forma, o currículo extraescolar, ou como preferimos chamar de currículo oculto, corresponde a uma alternativa para os educadores mediarem e promoverem uma perspectiva multicultural do ensino com os alunos. Assim, por ser um importante referencial nacional para a formulação dos currículos e das redes escolares dos Estados, do Distrito Federal e dos Municípios, inferimos que a Base Nacional precisa alinhar suas propostas pedagógicas com outras políticas e ações no âmbito referente à formação de professores, à elaboração de conteúdos educacionais e à avaliação.

De acordo com Santos et.al $(2019,248)$ :

A escola e, por conseguinte os atores sociais que estão inseridos no contexto escolar tem a desafiadora missão de refletir sobre esses aspectos, sobretudo na promoção da interação entre grupos de diferentes culturas enquanto viés de produção de conhecimento reconhecendo os vários processos construídos pela inter-relação cultural.

Diante do que foi posto, percebe-se que para enfrentar as dificuldades de se incorporar a diversidade cultural nas propostas curriculares da BNCC, é necessário a princípio, refletir sobre a contextualização do currículo, de forma a reestruturá-lo para conceber uma análise prática de como trabalhar as diferentes culturas de forma geral e inclusiva, buscando garantir a igualdade de oportunidades para os estudantes e evitar a supervalorização de determinada cultura dominante em detrimento de outra minoritária. Assim, é urgente a necessidade de uma reformulação crítica dos pressupostos curriculares presentes na Base para se promover a equidade e o respeito às diversidades sociais. 


\section{ABORDAGEM POLÍTICA E CULTURAL DO CURRÍCULO NA FORMAÇÃO DOCENTE}

Dentre as dificuldades relacionadas ao desenvolvimento de um currículo escolar voltado a abrangência da diversidade cultural, Moreira (2007) aborda a necessidade de se repensar a respeito da formação inicial e continuada dos professores, visto que nos últimos anos houve um importante movimento pela reformulação dos cursos de formação de profissionais da Educação Básica. Não restam dúvidas quanto à importância de se promover a formação de professores para que possam contribuir com o desenvolvimento de sujeitos autônomos, críticos e comprometidos com a democracia e a justiça social.

Nesse sentido, o discurso moral e ético também deve ser valorizado na formação docente e ser trabalhado no Projeto Político Pedagógico (PPP) das instituições de ensino, com a finalidade de resgatar novas formas de culturas e práticas sociais, na qual a escolarização seja parte de uma constante batalha por uma sociedade menos desigual (ALVES; SANTOS, 2017). No entanto, não adiantar falar em formação docente sem antes refletir sobre a relação entre as implicações curriculares e a valorização da atuação dos professores, bem como na melhoria das condições de trabalho e de infraestrutura das escolas, pois não é possível ter uma educação de qualidade sem o envolvimento dos docentes na produção do currículo (LOPES, 2018).

Como já enfatizamos, a BNCC necessita ser compreendida e trabalhada numa visão política cultural e democrática, sobretudo no ambiente escolar, onde as experiências e subjetividades devem ser contestadas para evitar a homogeneização didática e pedagógica (MOREIRA, 1995). Corroborando com esse pensamento, Vasconcelos (2002), discute algumas dimensões essenciais para os cursos de formação docente que irão ajudar a prática docente dos professores, sobretudo no que se refere a organização da coletividade e o relacionamento interpessoal para que o educador possua um olhar diferenciado, mais próximo do aluno, e ao mesmo tempo respeitando as diferentes dimensões culturais, ideológicas, de classe e de gênero existentes no âmbito escolar. 
Reforçando essas considerações, Moreira (2001, p. 3) considera que uma formação docente articulada com o caráter multicultural da sociedade no âmbito do currículo, "implica respeitar, valorizar, incorporar e desafiar as identidades plurais em políticas e práticas curriculares", nos permitindo inferir que uma prática pedagógica orientada multiculturalmente contra a homogeneização, dará voz a diferentes manifestações culturais, bem como aos diferentes significados de mundo e de sociedade no processo de formação de identidades.

$\mathrm{Na}$ visão desse autor, é de suma importância refletir sobre qual professor se deseja formar, pois é indiscutível a necessidade de uma formação docente comprometida com o engajamento social, posto que:

[...] a importância de um professor que, bem desempenhando seu papel de intelectual, procure tanto denunciar e desnaturalizar fatores opressivos e relações de poder assimétricas, como contribuir para o anúncio de alternativas que caminhem na contramão de visões e interesses hegemônicos (MOREIRA, 2001, p. 8).

Para concretizar essa discussão a respeito da formação docente voltada a uma abordagem de valorização multicultural do currículo escolar, o autor anteriormente mencionado, complementa que ao considerar tanto o exercício profissional dos professores, quanto aos processos de formação docente, necessitam combinar dimensões de ordem política, cultural e acadêmica, de tal modo a instigar e favorecer o compromisso com a construção de uma sociedade mais justa, libertadora e democrática. Assim, concordamos com Lopes (2018), ao explicitar que boa parte do investimento capital e intelectual dedicado a formulação da BNCC seria melhor aplicado, se destinado na promoção de melhorias das tradições curriculares, como a criação de parcerias entre Universidades e Secretarias de Educação estaduais e municipais para a formação docente em currículo e em melhorias nas condições de trabalho.

\section{CONSIDERAÇÕES FINAIS}

Conceber um currículo que atenda as formas de diversidade cultural é um desafio predominante nas escolas e na prática docente, na qual se tornou ainda mais difícil 
após a aprovação da Base Nacional, cuja abordagem mantêm sua ideologia pedagógica como instrumento de homogeneização e de incorporação à cultura dominante, em que as questões relacionadas a produção, seleção, distribuição, aprendizagem e avaliação do conhecimento escolar ficam limitadas ou até mesmo alienadas à ideologias hegemônicas relacionadas ao controle e dominação, ocasionando divergências e desvalorização das singularidades de milhares de instituições de ensino espalhadas no país, principalmente na relação entre professores, alunos, gestores, familiares e da sociedade em geral diante das experiências e práticas que deveriam ser escolhidas e mais valorizadas.

Diante das discussões levantadas, ficou claro a necessidade de uma contextualização do currículo escolar estabelecido pela BNCC, para atender a multiculturalidade social na educação. No entanto, essa abordagem constitui um desafio predominante na atualidade devido a manutenção de uma ideologia pedagógica ultrapassada e alienada às questões de controle e dominação. Assim, uma das possibilidades de prevenir a homogeneização do currículo está relacionada com a formação inicial e continuada de professores acerca dos pressupostos curriculares atuais, e compromissada com a valorização de uma prática pedagógica direcionada a diversidade cultural.

\section{REFERÊNCIAS}

ALVES, Manoel Messias Santos; SANTOS, Fernanda Viana dos. O currículo escolar pautado na diversidade cultural: algumas abordagens multiculturalistas na atualidade. Educon, Aracaju, v. 11, n. 01, p.16, set/2017.

BRASIL. Base Nacional Comum Curricular: Educação Infantil, Ensino Fundamental e Ensino Médio. Brasília: MEC/Secretaria de Educação Básica, 2018. Disponível em: http://basenacionalcomum.mec.gov.br/images/BNCC_EI_EF_110518_versaofinal_sit e.pdf. Acesso em: 11 out. 2019.

BRASIL. Constituição da República Federativa do Brasil (1988). Brasília, DF: Senado Federal, 1988.

Disponível em: 
http://www.planalto.gov.br/ccivil_03/constituicao/constituicaocompilado.htm. Acesso em: 11 out. 2019.

BRASIL. Lei de Diretrizes e Bases da Educação Nacional. № 9.394/96. Brasília: Congresso Nacional/MEC, $1997 . \quad$ Disponível em: https://www2.senado.leg.br/bdsf/bitstream/handle/id/70320/65.pdf?sequence=3. Acesso em: 11 out. 2019.

INEP, Instituto Nacional de Estudos e Pesquisas Educacionais Anísio Teixeira. Sistema de Avaliação da Educação Básica - Edição 2017. Projeto Básico, v. 6. Ministério da Educação, 2017.

LOPES, Alice Casimiro. Apostando na produção contextual do currículo. In: AGUIAR, M. A. S.; DOURADO, L. F.; SUANNO, M. A BNCC na contramão do PNE 2014-2024: avaliação e perspectivas. Recife: ANPAE, 2018.

MOREIRA, Antônio Flavio Barbosa. Currículo, cultura e formação de professores. Educar em Revista. n.17 Curitiba Jan./Jun. 2001. Disponível em: http://www.scielo.br/pdf/er/n17/n17a04.pdf. Acesso em: 11 out. 2019.

MOREIRA, Antônio Flavio Barbosa. Indagações sobre Currículo: Currículo, Conhecimento e Cultura. Brasília: MEC/SEB, 2007. Disponível em: http://portal.mec.gov.br/seb/arquivos/pdf/Ensfund/indag3.pdf. Acesso em: 11 out. 2019.

OLIVEIRA, I. A.; ARAÚJO, M. D.; CAETANO, V. N. S. Epistemologia e educação: reflexões sobre temas educacionais. Belém: PPGED-UEPA, 2012.

OLIVEIRA, Dagmar Braga de; et.al. Considerações sobre o conceito de educação e a formação do sujeito crítico na contemporaneidade. In: GUILHERME, W. D. A Educação no âmbito do político e de suas tramas 4. Ponta Grosa: Atena, 2019, 108114. E-book. Disponível em: https://www.atenaeditora.com.br/post-artigo/25793. Acesso em: 29 jul. 2020. 
SACRISTÁN, José Gimeno. O Currículo: Uma Reflexão sobre a Prática. Porto Alegre, Artmed, 2000.

SACRISTÁN, José Gimeno. O que significa o currículo? Em Saberes e incertezas sobre o currículo, SACRISTAN, José Gimeno. (org.) Porto Alegre, Penso, 2013.

SANTOS, José Elyton Batista dos; et.al. Diálogos entre ensino de ciências e multiculturalismo: um levantamento da produção nos ENPECS (1997-2015). In: GUILHERME, W. D. (Org.). A Educação no âmbito do político e de suas tramas 2. Ponta Grossa: Atena, 2019, p. 246-257. E-book. Disponível em: https://www.atenaeditora.com.br/post-artigo/25804. Acesso em: 29 jul. 2020.

SILVA, Tomaz Tadeu da. Documentos de Identidade: Uma Introdução às Teorias do Currículo. Belo Horizonte: Autêntica, 1999.

VASCONCELLOS, Celso dos Santos. Planejamento: Projeto de Ensino Aprendizagem e Projeto Político Pedagógico. Elementos metodológicos para a elaboração e realização. São Paulo: Libertad, 2002.

\section{APÊNDICE - REFERÊNCIA DE NOTA DE RODAPÉ}

4. Utilizamos as expressões "Base Nacional" ou "Base", no decorrer do texto, para nos referir à Base Nacional Comum Curricular.

Enviado: Julho, 2020.

Aprovado: Agosto, 2020. 